\title{
MoAb Bombesin (DTPA)
}

National Cancer Institute

\section{Source}

National Cancer Institute. MoAb Bombesin (DTPA). NCI Thesaurus. Code C29212.

A monoclonal antibody directed against the neurohormone bombesin that is conjug ated to diethylenetriaminepenta-acetic acid (DPTA), a bifunctional chelating agent that allows the antibody to be labeled with a metal species such as radioactive indium. Levels of bombesin, also known as gastrin releasing peptide (GRP), are elevated in lung and thyroid cancers, where the substance acts as an autocrine growth factor. (NCI04) 